\title{
BM] open Risk of developing disability in pre and post-multidrug therapy treatment among multibacillary leprosy: Agra MB Cohort study
}

\author{
Anil Kumar, Anita Girdhar, Bhavneswar Kumar Girdhar
}

To cite: Kumar A, Girdhar A, Girdhar BK. Risk of developing disability in pre and post-multidrug therapy treatment among multibacillary leprosy: Agra MB Cohort study. BMJ Open 2012;2:e000361. doi:10.1136/

bmjopen-2011-000361

- Prepublication history for this paper is available online. To view these files please visit the journal online (http:// dx.doi.org/10.1136/ bmjopen-2011-000361).

Received 31 August 2011 Accepted 17 February 2012

This final article is available for use under the terms of the Creative Commons Attribution Non-Commercial 2.0 Licence; see http://bmjopen.bmj.com

Epidemiology and Clinical Divisions, National JALMA Institute for Leprosy and Other Mycobacterial Diseases (ICMR), Taj Ganj, Agra, Uttar Pradesh, India

Correspondence to Dr Anil Kumar; dranil250158@gmail.com

\section{ABSTRACT}

Objectives: If leprosy is a public health problem, it is due to the disabilities it causes. Surprisingly little is known about the risk of disabilities. Even now, mainly cross-sectional studies report disability prevalence. The present study aims to report the risk of disability in pre and post-WHO multidrug therapy (MDT) in multibacillary leprosy patients and to assess the extent of the incidence of disability.

Methods: The study design is prospective and the setting is an institutional field area. Patients were detected during 2001-6 field surveys. Of the 289 multibacillary patients, 146 completed the study. Both sexes were involved. The primary outcome planned was to study cure of disease, relapses and disability in patients receiving MDT. The secondary outcome was to measure reaction and default. Assessment was done clinically. Data have been analysed using SPSS software, logistic, survival analysis was performed and the $\chi^{2}$ test of significance was used.

Results: An important risk factor was found to be three or more nerves involved with odds of 3.73 (1.24-11.2), and delay in treatment; 2.27 (1.04-4.96) at the pre-MDT stage and three or more nerves involved with odds of $2.81(1.0-7.9)$ at the post-MDT stage. The incidence of disability was found to be $2.74 /$ 100 person-years; 2.69 in the MDT arm and 2.84 in defaulters, with slightly higher disability among early defaulters (3.08) than among late defaulters (2.30). The study suggests that the incidence of disability could be slightly higher if treatment is not completed. Conclusion: Early treatment for leprosy is a must for reducing the risk of disability, and treatment delay would increase the risk of disability. It is important to note that the incidence of disability between defaulters and those completing treatment was not found to be significantly different.

If leprosy is a public health problem, it is due to the disabilities it causes. It was surprising to note that this being so important, very little was known about the risk of disabilities ${ }^{1}$ and even now there are mainly cross-sectional studies at the population level that reports disability prevalence among leprosy patients.

\section{ARTICLE SUMMARY}

\section{Article focus}

- What are the risk factors associated with disability at the pre-MDT and post-MDT stage?

- What is the risk of disability among leprosy patients, patients completing treatment versus defaulters?

- Do early defaulters have a higher incidence of disability than late defaulters?

Key messages

- This study clearly demonstrates that risk factors for disability at detection and in a prospective cohort are the same, ie, an increasing number of nerves thickening. It also reveals that the incidence of disability although high among defaulters (2.84/100 person-years) is not significantly higher than in those completing treatment (2.42/100 person-years); nor does it differ significantly among early versus late defaulters (3.08 vs 2.30). In addition, it shows that treatment with ROM has much better prevention than in MDT groups. All this together implies that even a few months of treatment could be as good as completing treatment as far as the development of disability is concerned, but treatment must be started.

Strength and limitations of this study

- The strength of the study is that it is based on a closely followed prospective cohort for a good length of time and patients were clinically assessed and monitored. However, one limitation could be that the ROM arm could not be completed due to WHO withdrawal. This could have provided more comparable data.

The prevalence of disability, however, varies significantly from one study to another. In the Malawi study, disability prevalence varied from $20 \%$ to $10 \%$ during $1973-87 .^{1}$ The studies performed in India $^{2-6}$ reported a visible deformity rate from $2.8 \%$ to $24.3 \%$ among cases at registration or detection in population surveys. However, very few studies on the risk of developing disabilities have 
been undertaken. Although the Malawi study ${ }^{1}$ had reported the risk of developing disabilities as 5/1000 person-years during the pre-multidrug therapy (MDT) era, and the south India study ${ }^{2}$ observed a disability rate of $6.8 \%$, this was a crude estimate without referring to time. The risk of developing disabilities is also very important for the national programme on the prevention of disabilities.

This study was therefore attempted to assess the risk/ incidence of developing disability among those leprosy patients who had no disability at the time of detection in field surveys but developed it during the years of follow-up after completion of WHO MDT.

\section{DESIGN AND METHODS}

\section{Study site, field setting and duration of study}

The study was started in our field area in the Agra district of Uttar Pradesh on patients detected in field surveys under several studies on the prevalence of leprosy during 2001-6. ${ }^{3-6}$ The Agra district is located $200 \mathrm{~km}$ away from Delhi and spreads in the radius of $100 \mathrm{~km}$ on either side in length and borders with the districts of Itawa and Firozabad on the eastern side, Mathura and Bharatpur on the north-west side and Gwalior and Dholpur on the south side. Several studies have been undertaken because the district was highly endemic for leprosy, with a prevalence of 16.4/10 000 during 2001-3 and 7/10 000 during 2004-6. The present study is based on patients detected in such surveys and all patients were followed up to April 2011.

\section{Inclusion/exclusion criteria of patients for the study}

Newly detected leprosy patients diagnosed clinically as multibacillary leprosy were included in the study. This included patients with more than five skin lesions, either erythmatous or hypopigmented with definite impairment or loss of sensation (tested with a ballpoint pen) or more than two thickened nerves. None of the patients had taken leprosy treatment earlier. Children younger than 5 years and adults above 70 years were treated as per the norm but were not included in the study and so were pregnant and lactating women.

\section{Cohort size and treatment allocation and assessment on follow-up}

Two hundred and ninety-three leprosy cases with multibacillary leprosy were detected. Of these 293, four patients did not start the treatment. The study was initially aimed to study the difference in the outcome of the two treatment arms (100 patients in each arm), ie, rifampicin $600 \mathrm{mg}$, ofloxacin $400 \mathrm{mg}$ and minocycline $200 \mathrm{mg}$ (ROM) for adults and half of it for children $(<15$ years) as recommended by WHO versus WHO standard MDT (rifampicin, ofloxacin and dapsone) given monthly for 12 months. As WHO suddenly withdrew the ROM supply in 2003, only a small number of patients (22) were randomly allocated (using a random numbers table) to the ROM arm by then and later on all the cases detected were put on MDT. Therefore, this study now aimed at studying the risk of relapse and disability among MDT-treated cases and the ROM arm was not included in the study. An attempt was also made to compare the risk of disability among those completing treatment compared with those who defaulted; either early (within 6 months) or late (during 6-11 months). All the cases that were started on treatment were followed up monthly to treatment completion, 6-monthly up to 3 years and then annually to the end of the study. Disability grade 1 was defined as the patient developing anaesthesia in the palm or sole tested with a ballpoint pen and grade 2 as visible deformity in either the hands, feet or eyes (lagophthalmas). During this time, all cases of clinical relapse, reaction and development of disability

Table 1 Prevalence of grade 2 disability at detection in multibacillary leprosy patients by demographic and clinical status, Agra district (Uttar Pradesh) India during 2001-6

\begin{tabular}{|c|c|c|}
\hline \multirow[b]{2}{*}{ Characteristics } & \multicolumn{2}{|c|}{ MDT arm (267) } \\
\hline & Cases & $\begin{array}{l}\% \text { Grade } 2 \\
\text { disability }\end{array}$ \\
\hline \multicolumn{3}{|l|}{ Age, years } \\
\hline$\leq 14$ & 17 & 5.9 \\
\hline $15-24$ & 25 & 4.0 \\
\hline $25-34$ & 40 & 5.0 \\
\hline $35-54$ & 108 & 13.9 \\
\hline$>54$ & 77 & 10.4 \\
\hline Total & 267 & 10.1 \\
\hline Mean (SEM) & $43.4(1.1)$ & \\
\hline \multicolumn{3}{|l|}{ Sex } \\
\hline Male & 163 & 14.1 \\
\hline Female & 104 & 3.9 \\
\hline \multicolumn{3}{|c|}{ Delay in detection, months } \\
\hline$\leq 12$ & 67 & 6.0 \\
\hline $13-36$ & 103 & 8.7 \\
\hline$>36$ & 97 & 14.4 \\
\hline \multicolumn{3}{|l|}{ Patches } \\
\hline 0 & 12 & 50.0 \\
\hline $1-5$ & 16 & 25.0 \\
\hline $6-10$ & 84 & 3.6 \\
\hline$>10$ & 155 & 9.0 \\
\hline \multicolumn{3}{|l|}{ Nerves } \\
\hline $0-2$ & 99 & 4.0 \\
\hline $3-5$ & 101 & 11.9 \\
\hline$>5$ & 67 & 16.4 \\
\hline \multicolumn{3}{|l|}{ Clinical status } \\
\hline BT/BTR & 131 & 3.8 \\
\hline BB/BBR & 74 & 5.4 \\
\hline $\mathrm{BL} / \mathrm{LL}$ & 51 & 25.5 \\
\hline $\mathrm{N}$ & 11 & 45.5 \\
\hline \multicolumn{3}{|l|}{ Treatment status } \\
\hline Defaulters & 92 & 8.7 \\
\hline Completed & 175 & 10.9 \\
\hline \multicolumn{3}{|l|}{ Smear } \\
\hline Positive & 27 & 7.4 \\
\hline Negative & 138 & 6.5 \\
\hline Not done & 102 & 15.7 \\
\hline
\end{tabular}


(grade 1 and grade 2) were recorded after medical confirmation and necessary medical relief was either provided or they were referred (see flow chart).

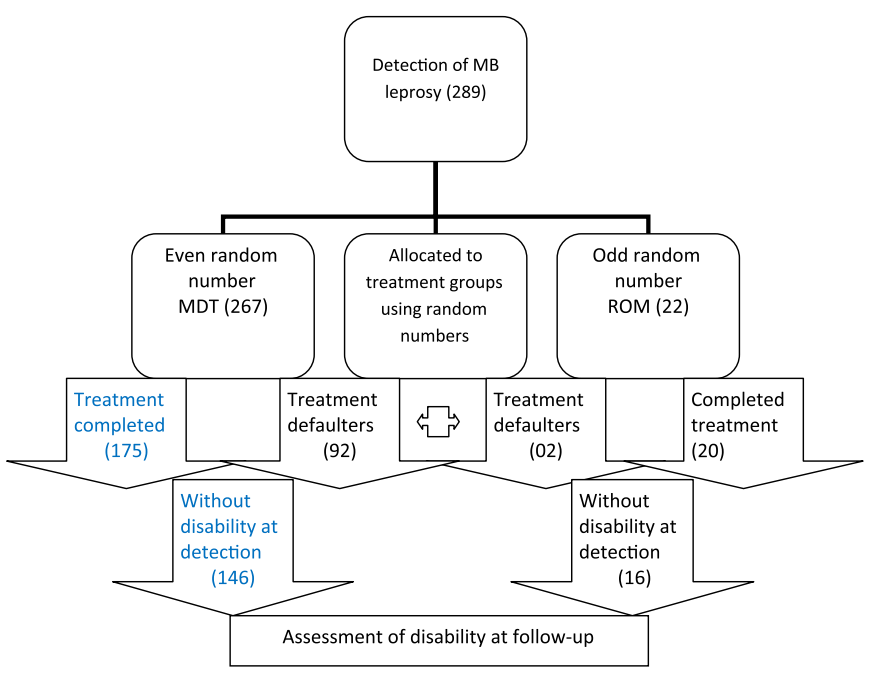

Defining some parameters

A leprosy patient detected with leprosy-related disability at the time of detection in the field survey was defined as prevalence of disability. The occurrence of disability detected at follow-up in previously detected leprosy cases without disability at that time was defined as incidence of disability. Delay at detection or treatment is the same, ie, duration of untreated disease as reported at first detection.

\section{Ethics approval and informed consent}

Ethics approval was granted by the institutional ethical committee, which was being informed periodically about the progress of the work. All the patients were informed about the possible side effects, remedies and benefits. Although the treatment given was a WHO standard regimen, for reasons of follow-up etc the patients were asked to consent and then they were put on respective treatment. In case of children, consent of their parents was obtained.

Table 2 CID by demographic and clinical status at follow-up among multibacillary leprosy patients by treatment compliance status, Agra district (Uttar Pradesh) India

\begin{tabular}{|c|c|c|c|c|c|c|}
\hline \multirow[b]{2}{*}{ Charaecterstics } & \multicolumn{2}{|c|}{ Completed treatment } & \multicolumn{2}{|c|}{ Defaulters } & \multicolumn{2}{|l|}{$\chi^{2}$ with $p$ value } \\
\hline & Cases & CID rate & Cases & CID rate & Completed treatment & Defaulters \\
\hline \multicolumn{7}{|l|}{ Age, years } \\
\hline$\leq 14$ & 12 & 0 & 2 & 0 & $>0.05$ & $>0.05$ \\
\hline $15-24$ & 15 & 6.7 & 3 & 33.3 & & \\
\hline $25-34$ & 30 & 9.7 & 9 & 0 & & \\
\hline $35-54$ & 64 & 15.6 & 25 & 12.0 & & \\
\hline$>54$ & 41 & 7.3 & 20 & 20.0 & & \\
\hline Total & 162 & 10.5 & 59 & 13.6 & & \\
\hline \multicolumn{7}{|l|}{ Sex } \\
\hline Male & 101 & 12.9 & 28 & 14.3 & $>0.05$ & $>0.05$ \\
\hline Female & 61 & 6.6 & 31 & 12.9 & & \\
\hline \multicolumn{7}{|c|}{ Delay in treatment, months } \\
\hline$\leq 12$ & 44 & 6.8 & 14 & 7.1 & $>0.05$ & $>0.05$ \\
\hline $13-36$ & 63 & 11.1 & 26 & 11.5 & & \\
\hline$>36$ & 55 & 12.7 & 19 & 21.1 & & \\
\hline \multicolumn{7}{|l|}{ Patches } \\
\hline 0 & 5 & 60.0 & 0 & 0 & $15.0,0.002$ & $>0.05$ \\
\hline $1-5$ & 6 & 0 & 4 & 0 & & \\
\hline $6-10$ & 62 & 6.5 & 13 & 0 & & \\
\hline$>10$ & 90 & 11.1 & 42 & 19.0 & & \\
\hline \multicolumn{7}{|l|}{ Nerves } \\
\hline $0-2$ & 66 & 4.8 & 28 & 7.1 & $>0.05$ & $7.7,0.021$ \\
\hline $3-5$ & 60 & 11.7 & 17 & 5.9 & & \\
\hline$>5$ & 39 & 17.9 & 14 & 35.7 & & \\
\hline \multicolumn{7}{|l|}{ Clinical status } \\
\hline BT/BTR & 94 & 4.3 & 24 & 8.3 & $19.6,<0.001$ & $>0.05$ \\
\hline $\mathrm{BB} / \mathrm{BBR}$ & 38 & 13.2 & 23 & 21.7 & & \\
\hline BL/LL & 25 & 20.0 & 12 & 8.3 & & \\
\hline $\mathrm{N}$ & 5 & 60.0 & 0 & 0 & & \\
\hline \multicolumn{7}{|l|}{ Smear } \\
\hline Positive & 101 & 8.9 & 28 & 17.9 & $>0.05$ & $>0.05$ \\
\hline Negative & 19 & 10.5 & 4 & 0 & & \\
\hline Not done & 42 & 14.3 & 27 & 11.1 & & \\
\hline
\end{tabular}


Table 3 Risk factors for prevalence of disability at detection (pre-MDT stage)

\begin{tabular}{|c|c|c|c|}
\hline & OR (95\% Cl) & OR $(95 \% \mathrm{CI})$ & OR $(95 \% \mathrm{Cl})$ \\
\hline \multicolumn{4}{|l|}{ Nerves } \\
\hline $0-2$ & 1.0 & 1.0 & 1.0 \\
\hline 3 or more & $4.53(1.54$ to 13.4$)$ & $3.87(1.30$ to 11.6$)$ & $3.73(1.24$ to 11.2$)$ \\
\hline \multicolumn{4}{|l|}{ Age, years } \\
\hline$<35$ & - & 1.0 & 1.0 \\
\hline$\geq 35$ & - & $2.49(0.83$ to 7.50$)$ & $2.35(0.77$ to 7.12$)$ \\
\hline \multicolumn{4}{|c|}{ Delay in treatment, months } \\
\hline$\leq 36$ & - & - & 1.0 \\
\hline$>36$ & - & - & $2.27(1.04$ to 4.96$)$ \\
\hline Standardised for & None & Age & Age and delay in treatment \\
\hline
\end{tabular}

\section{Statistical methods}

The comparison of patients developing disability was performed using survival analysis and the log rank test to test the significance using SPSS V.12 software and Fisher's exact test or the $\chi^{2}$ test of significance used to compare proportions. ${ }^{7}$ The logistic regression analysis was done to undertake risk factor analysis.

\section{RESULTS}

Demographic characteristics of patients

Patients of all ages were detected in surveys. The mean age was 43.4 years (SEM 1.1) with a median of 45 years. Most patients (69.3\%) were aged 35 years and above and only $6.4 \%$ were children. Male patients in this study accounted for $61.0 \%$ of the total 267 cases started on multibacillary MDT. At the time of survey, $25.1 \%$ of patients were those who reported acquiring leprosy during the past 12 months, $38.6 \%$ in the past $12-36$ months and the rest had had the disease for over 36 months.

\section{Prevalence of disability at detection}

The prevalence of grade 2 disability (visible) was found to be $10.1 \%$. The prevalence of grade 2 disability seems to increasee slowly with increased age, and male patients had greater disability $\left(14.1\right.$ vs $\left.3.8, \chi^{2}=7.4, p=0.007\right)$ than the female patients. The prevalence of disability also increased among patients who delayed treatment for a longer period particularly beyond 36 months $\left(\chi^{2}=6.2\right.$, $\mathrm{p}=0.032$ ). Significantly greater disability was noted among patients with three or more thickened nerves $\left(\chi^{2}=7.3, p=0.026\right)$, and among patients with an advanced clinical stage of disease (BL (borderline lepromatous)/ LL (lepromatous) or neuritic) $\left(\chi^{2}=37.9, \mathrm{p}=0.000\right)$ than among those with early stage disease (BT (borderline tuberculoid)/BB (borderline borderline)). However, the prevalence of disability did not vary significantly among patients who defaulted from treatment compared with those who completed treatment $\left(\chi^{2}=0.45, \mathrm{p}=0.80\right)$ and by smear status $\left(\chi^{2}=4.6, \mathrm{p}=0.10\right)$ see table 1 .

\section{Crude incidence of disability}

The crude incidence of disability (CID) is presented in table 2. The CID was observed to be $13.6 \%$ among treatment defaulters, greater than $10.5 \%$ among those who completed treatment, but was not significantly different $(p>0.05)$ nor did it increase significantly by the age of the patients $(p>0.05)$. Although men had a higher incidence of disability than women (14.3 vs 12.9 in defaulters and 12.9 vs 6.6 in the completing treatment group), the difference was not significant $(p>0.05)$. The CID was found to be significantly higher among MDT patients with neuritic leprosy (patch 0 ) or in those with more than 10 patches $\left(\chi^{2}=15.0, p=0.002\right)$. The patients with three or more thickened nerves who still defaulted had significantly greater disability $\left(\chi^{2}=7.7, \mathrm{p}=0.021\right)$ in comparison with those patients on MDT who completed their

Table 4 Risk factors for incidence of disability post-MDT

\begin{tabular}{llll}
\hline & OR $(95 \% \mathbf{~ C l})$ & OR $(95 \% \mathbf{~ C l})$ & OR (95\% Cl) \\
\hline $\begin{array}{l}\text { Nerves } \\
\quad-2\end{array}$ & 1.0 & 1.0 & 1.0 \\
$\quad 3$ or more & $3.05(1.10$ to 8.48$)$ & $2.84(1.01$ to 8.0$)$ & $2.81(1.0$ to 7.90$)$ \\
$\begin{array}{l}\text { Age, years } \\
\quad 35\end{array}$ & - & 1.0 & 1.0 \\
$\quad \geq 35$ & - & $1.63(0.57$ to 4.58$)$ & $1.64(0.58$ to 4.68$)$ \\
$\begin{array}{l}\text { Delay in treatment, months } \\
\quad 36\end{array}$ & - & - & 1.0 \\
$\quad>36$ & - & - & $1.22(0.57$ to 2.61$)$ \\
Standardised for & None & Age & Age and delay in treatment \\
\hline MDT, multidrug therapy. & & &
\end{tabular}


Table 5 Incidence of disability/1000 person-years of follow-up

\begin{tabular}{|c|c|c|c|c|c|}
\hline Treatment group & Cases & $\begin{array}{l}\text { Mean years } \\
\text { survival time }\end{array}$ & Person-years & $\begin{array}{l}\text { Disability } \\
\text { developed in }\end{array}$ & $\begin{array}{l}\text { Incidence/100 } \\
\text { person-years }\end{array}$ \\
\hline Completed treatment MDT & 146 & 4.08 & 594.7 & 16 & 2.69 \\
\hline Defaulters of MDT & 59 & 4.78 & 281.9 & 08 & 2.84 \\
\hline $\begin{array}{l}\text { Early ( }<6 \text { months of } \\
\text { treatment) }\end{array}$ & 38 & 5.12 & 194.9 & 06 & 3.08 \\
\hline $\begin{array}{l}\text { Late }(6-11 \text { months of } \\
\text { treatment) }\end{array}$ & 21 & 4.14 & 87.0 & 02 & 2.30 \\
\hline All & 205 & 4.28 & 876.6 & 24 & 2.74 \\
\hline
\end{tabular}

treatment. Patients in the MDT arm who had disease of a high clinical spectrum such as BL/LL/neuritic leprosy were observed to have a significantly greater incidence of disability $\left(\chi^{2}=19.6, \mathrm{p}<0.001\right)$. However, no difference was found by the smear positivity status of patients.

Risk factors for prevalence of disability (pre-MDT stage) Using logistic regression analysis, an attempt was made to assess the role of risk factors known to be responsible for causing disability. It was found that patients with the involvement of three or more nerves had a 4.53 times higher risk of disability (OR 4.53, 95\% CI 1.54 to 13.4) presenting at detection, and after adjusting the effect of age and delay in treatment, this showed (OR 3.73, 95\% CI 1.24 to 11.2 ) than in others. The second highest risk was found for the factor 'delay at detection' for treatment beyond 36 months, ie, OR 2.27, 95\% CI 1.04 to 4.96 , compared with those who started treatment within 36 months of having disease-adjusted for age (table 3).

Risk factors for incidence of disability (post-MDT stage) The risk of the incidence of disability was assessed among those who were free from disability at the time of

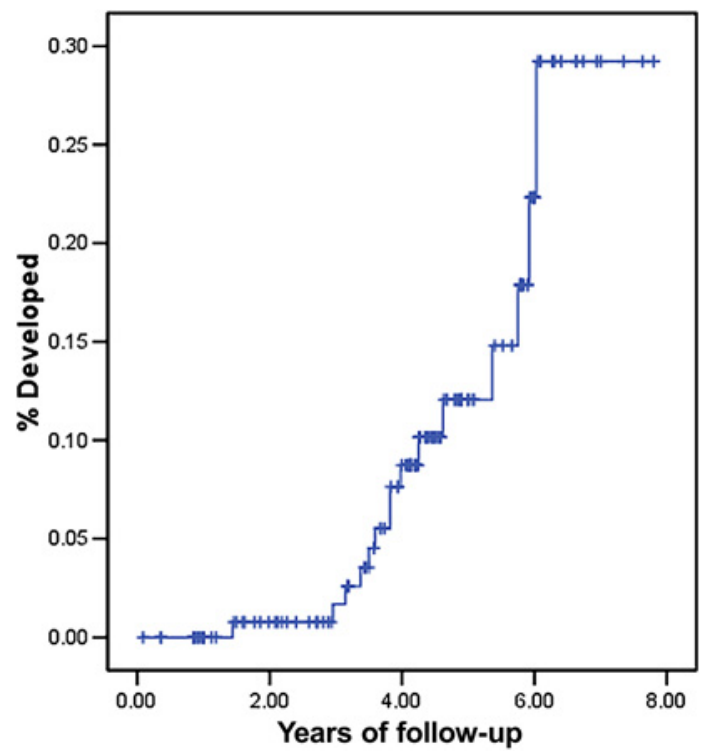

Figure 1 Incidence of disability in multibacillary leprosy patients who completed treatment. detection. It was found that the incidence of disability was high (OR $3.05,95 \%$ CI 1.10 to 8.48 ) among patients with three or more nerves involved and remained so (OR 2.81, 95\% CI 1.0 to 7.9) when standardised for age and delay in treatment (table 4 ).

\section{Incidence of disability}

A detailed analysis of the incidence of disability has been presented using survival analysis among different groups. The overall incidence of disability was found to be 2.74/100 person-years with a mean follow-up of 4.28 years after treatment completion or from the point of default (table 5). The incidence of disability was 2.69/100 person-years during a mean follow-up of 4.08 years in those patients completing MDT and $2.84 / 100$ person-years during a mean of 4.78 years after default (see figures 1 and 2).

The comparison of the incidence (hazard) curve by years of follow-up did not suggest a significant difference between the two treatment groups (log rank test 0.02 , $\mathrm{p}=0.88)$.

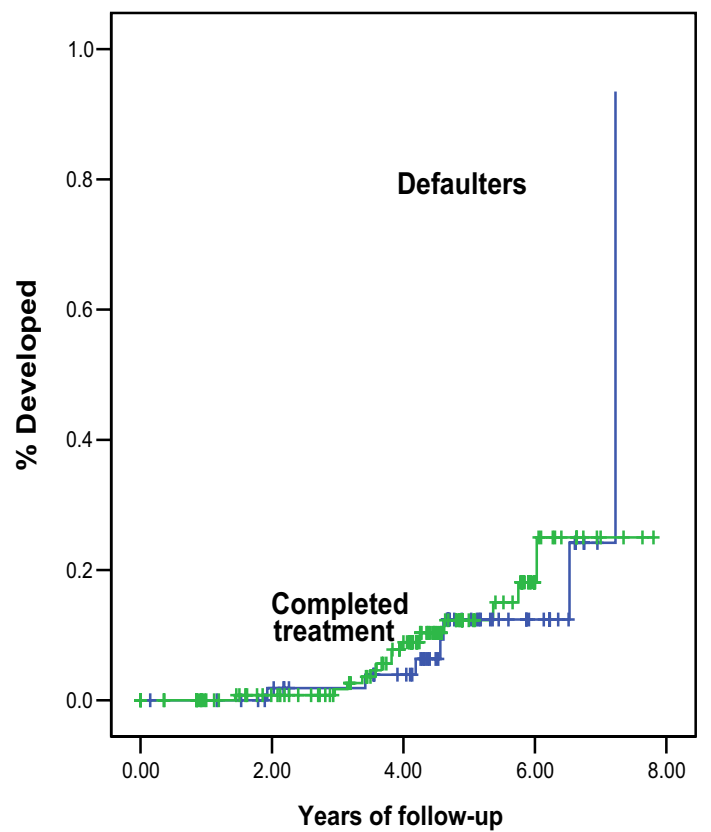

Figure 2 Risk of developing disability among multibacillary leprosy patients post-multidrug therapy by treatment compliance. 


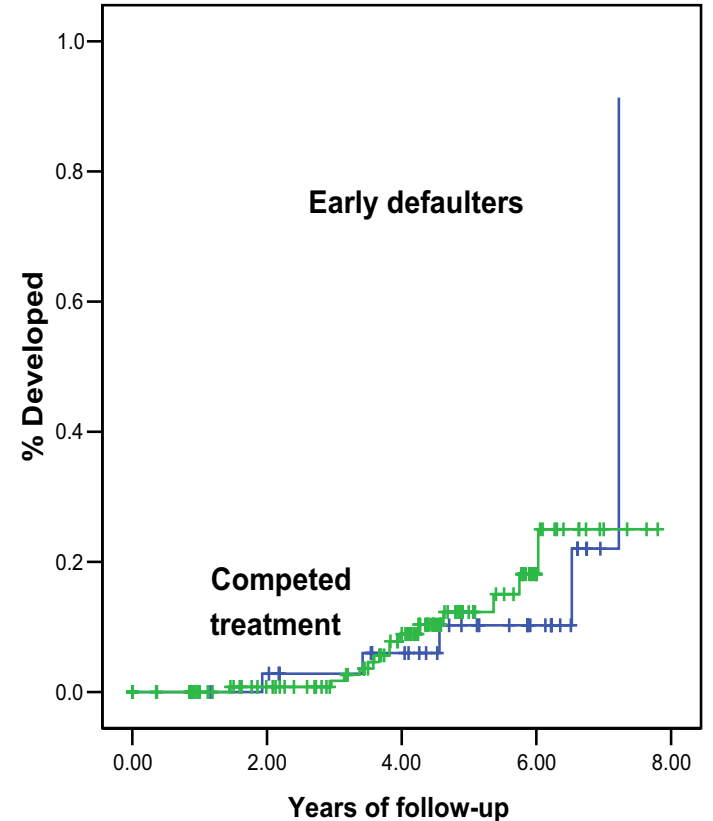

Figure 3 Risk of developing disability among multibacillary leprosy patients post-multidrug therapy.

A further analysis between early defaulters and late defaulters, although showing that early defaulters had the greatest incidence of disability (3.08/100 personyears) compared with 2.3/100 person-years in the group of late defaulters, but the incidence curve over the years of follow-up did not differentiate between the two statistically $(\mathrm{p}>0.05)$ (see figures 3 and 4 ).

\section{DISCUSSION}

This study provides a unique opportunity to assess the role of factors associated with the prevalence of disability

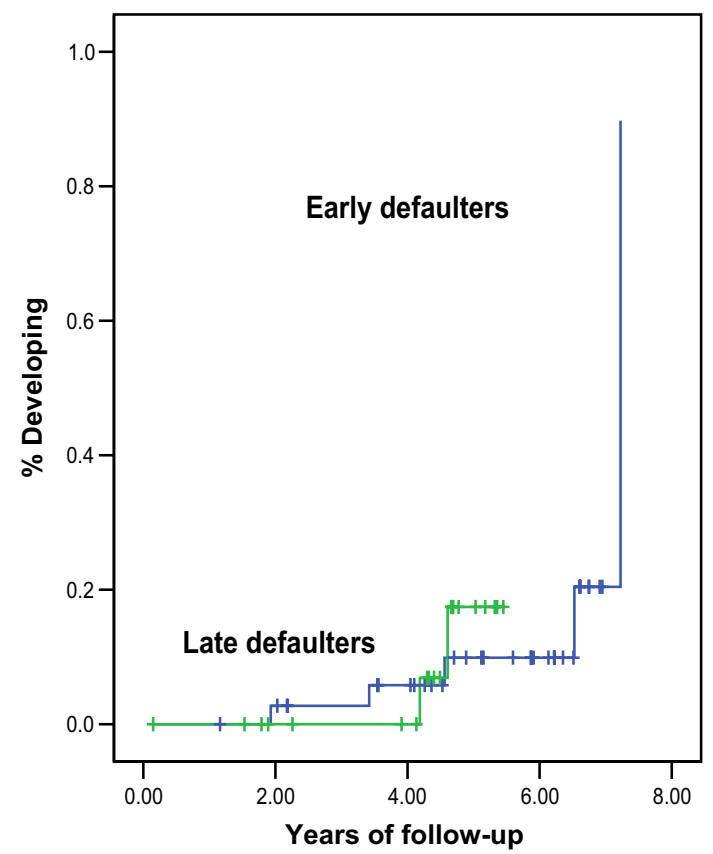

Figure 4 Risk of developing disability among multibacillary leprosy patients who defaulted from multidrug therapy. at a case detection stage in active surveys and also the incidence of disability when patients of varying treatment status are followed up for years. The risk factors for the development of disability among multibacillary patients appeared to be almost similar with increased nerve thickening (three or more nerves) as the number one risk factor, and delay in treatment beyond 36 months was the number 2 risk factor. A study conducted to assess the risk of paralytic deformity (grade 2 and above) among cases detected in surveys had shown that patients with skin lesions who also had three to five nerves involved were found to have a very high risk (OR 33.4) of deformity. ${ }^{8}$ However, the patients with neuritic leprosy (no skin lesions) with delay in diagnosis for treatment of beyond 5 years had 17.5 times (OR) the risk of developing deformity than among those with a lesser delay. ${ }^{8}$

The incidence of disability among these patients was found to be 2.74/100 person-years of follow-up; 2.69 in the MDT arm and 2.84 in treatment defaulters, with $33.9 \%$ (3.08 vs 2.30 ) greater disability among early defaulters (3.08) and 2.30 among late defaulters. The study therefore clearly suggests that the incidence of disability could be only slightly higher $6 \%$ (2.84 vs 2.69 ) in the group completing the required MDT than in those defaulting. The risk of disability in the present study was found to be higher than in the Malawi study (5/1000 person years). ${ }^{1}$ The CID in this study was also higher $(10.5 \%)$ among those completing MDT treatment than $6.8 \%$ in the south India study ${ }^{2}$ conducted during 1985-92. However, the reasons for the higher incidence of disability in this study are not clearly known. One of the possible reasons could be that pathways for disabilities are set in before the treatment started, and thus the occurrence of disability could not be altered. Second, once the disease affects an individual, the treatment may not be able to prevent disability. However, in the absence of proper studies, these are just possibilities.

\section{CONCLUSION}

The important conclusion of the study is that the initiation of treatment for leprosy is a must for reducing the risk of the incidence of disability, and delays in initiating treatment would increase the risk of disability by many fold. It is important to note that the incidence of disability between defaulters and those completing treatment was not found to be significantly different.

Acknowledgements The authors gratefully acknowledge the help extended by the institute by providing an internal grant for the study. Thanks are also due to all patients who cooperated in the study and the paramedic workers and district leprosy officer for their support.

Contributors Although all authors were responsible for the conception, design and acquisition of data, drafting, revising and final approval of the article, AK played the lead role in planning, conducting the field study, analysis, writing revision and submission; AG was responsible for clinical evaluation and BKG for clinical monitoring and report preparation.

Funding This study was supported by an institutional grant from the National JALMA Institute for Leprosy, Taj Ganj, Agra. No specific funding from external agencies was asked for. 
Competing interests None.

Patient consent Obtained.

Ethics approval Ethics approval was granted by the institutional ethical committee, which was being informed periodically about the progress of the work.

Provenance and peer review Not commissioned; externally peer reviewed.

Data sharing statement No extra data.

\section{REFERENCES}

1. Ponnighaus IM, Boerrigter G, Fine PEM, et al. Disabilities in leprosy patients ascertained in a total population survey in Karonga District, Northern Malawi. Lep Rev 1990;61:366-74.
2. Selvaraj G, Prabhakar N, Muliyil J, et al. Incidence of disabilities among multibacillary cases after initiation of multidrug therapy and factors associated with the risk of developing disabilities. Ind J Lepr 1998;70(Suppl):11S-16S.

3. Kumar A, Yadav VS, Girdhar A, et al. Some epidemiological observations on leprosy in Agra, India. Int J Lepr 2001;69:234-40.

4. Kumar A, Girdhar A, Girdhar BK. Epidemiology of leprosy in urban Agra, India. Lepr Rev 2003;74:31-4.

5. Kumar A, Girdhar A, Girdhar BK. Prevalence of leprosy in Agra district (U.P.) India during 2001-2003. Int J Lepr 2005;73:115-21.

6. Kumar A, Girdhar A, Chakma JC, et al. A rapid survey for leprosy in Agra district (2004-06): epidemiological observations. J Commun Dis 2008:40:277-84.

7. Le Chap T. Applied Catagorical Data analysis. USA: John Wiley \& Sons, 1998.

8. Kumar A, Girdhar A, Girdhar BK. Nerve thickening in leprosy patients and risk of paralytic deformities: a field based study in Agra, India. Lepr Rev 2004;75:135-42. 